\title{
Tourism Memory Characteristics Scale: Development and Validation
}

\author{
Youngsoo Kimª, Manuel Alector Ribeiro*a,b,c ${ }^{\text {a }}$ Gang Li ${ }^{\text {a }}$ \\ a. School of Hospitality \& Tourism Management, Faculty of Arts and Social Science, University \\ of Surrey, Guildford, Surrey, United Kingdom \\ b. School of Tourism and Hospitality, University of Johannesburg, Johannesburg, South Africa \\ c. Research Centre for Tourism, Sustainability and Well-being (CinTurs), Universidade do \\ Algarve, Faculty of Economics, Campus de Gambelas, Faro, Portugal
}

Youngsoo Kim, Youngsoo.kim@surrey.ac.uk (Y. Kim). Youngsoo Kim is a PhD researcher in School of Hospitality and Tourism Management, University of Surrey, Guildford, GU2 7XH, UK.

*Manuel Alector Ribeiro (Correspondence), m.ribeiro@surrey.ac.uk (M.A. Ribeiro). Dr. Manuel Alector Ribeiro is a Lecturer in School of Hospitality and Tourism Management, University of Surrey, Guildford, GU2 7XH, UK.

Gang Li, g.li@surrey.ac.uk (G. Li). Dr. Gang Li is a Professor of Tourism Economics and Director of the Research Centre for Competitiveness of the Visitor Economy, University of Surrey, Guildford, GU2 7XH, UK.

\begin{abstract}
Recall of tourism experiences is a decisive factor in tourists' future behavior and decision making when choosing destinations. Understanding the phenomenology of tourism memory can enable tourism organizations to enter a more competitive marketplace. Although extensive literature has addressed how to provide memorable tourism experiences, limited studies have focused on the autobiographical memories associated with these experiences. This research employed rigorous scale development procedures to establish the Tourism Memory Characteristics Scale (TMCS). Findings point to a seven-dimension scale consisting of accessibility, trip details, vividness, sensory details, valence, emotional intensity, and sharing. Tourism memory characteristics were found to support the scale's dimensional structure, validity, and reliability. It was also found that tourism memory influences revisit intention and word of mouth. Results present opportunities for tourism organizations to capture the fundamental characteristics of their products by using the TMCS.
\end{abstract}

Keywords: tourism experiences, autobiographical memory, phenomenology, tourism memory characteristics, scale development

\footnotetext{
${ }^{1}$ This article should be cited as follows:

Kim, Y., M. A. Ribeiro, G. Li (2021). Tourism Memory Characteristics Scale: Development and Validation. Journal of Travel Research, 1-19. https://doi.org/10.1177/00472875211033355.

Acknowledgements: This work is partially financed by Portuguese Funds provided by FCT-Fundação para a Ciência e a Tecnologia (Foundation for Science and Technology, Portugal) through project UIDB/04020/2020. The authors would like to thank the editor and the anonymous reviewers for their comments and suggestions which help to improve this paper greatly.
} 


\section{Introduction}

A trip, an amalgam of multiple events that tourists experienced, becomes a key source of tourism memory. Tourism memory is perceived as a seminal factor to predict customer behavior (Yin, Poon, and $\mathrm{Su}$ 2017). With an overarching goal of providing memorable experiences for tourists, researchers have striven to understand tourism experiences that are compelling enough to be remembered (J. H. Kim, Ritchie, and McCormick 2012). Recently, the concept of a shared memory economy was proposed by Wood (2020) who claimed that memories are "the most valuable commodity" that the tourism industry can offer. Given the importance of memory, tourism studies have advanced an understanding of tourism experience and its link to memory in the following areas: memorable tourism experiences (J. H. Kim 2010; J. H. Kim, Ritchie, and McCormick 2012; Tung and Ritchie 2011a), tourists' emotional experiences (Rahmani, Gnoth, and Mather 2019), functions of autobiographical memory (H. Kim and Chen 2019), autobiographical memory evocation (Yin, Poon, and Su 2017), tourist sensory memory (Agapito, Pinto, and Mendes 2017; Ballantyne, Packer, and Sutherland 2011; Lv, Li, and McCabe 2020), shared memory (Jepson, Stadler, and Spencer 2019), and tourism autobiographical memory (Jorgenson et al. 2019).

Memory underpins essential cognitive processes, playing pivotal roles in understanding individuals' recall of tourism experiences in which they were personally involved (Tung and Ritchie 2011a). In examining the relationship between memorable tourism experiences and memory, the phenomenological characteristics of autobiographical memory are often considered (J. H. Kim 2010; H. Kim and Chen 2021). Specifically, autobiographical memory stores episodic and semantic information about one's past (Conway 2005; Piolino et al. 2002). The phenomenology of autobiographical memory is associated with what individuals experience consciously during the retrieval of autobiographical memories (Boyacioglu and Akfirat 2015). Thus, the phenomenology of autobiographical memory allows researchers to understand major components of memory on individuals' recall of experienced events (Sutin and Robins 2007). Despite the notable benefits of memory phenomenology, only some memory dimensions have been used to investigate their relationships with salient antecedents such as memorable tourism experiences (J. H. Kim 2010) and destination attributes (J. H. Kim 2020), and some consequences such as behavioral intentions (Agapito, Pinto, and Mendes 2017; J. H. Kim and Youn 2017; Yin, Poon, and Su 2017).

In the psychology domain, there have been a number of memory dimensions and memory scales, such as Sutin and Robins's (2007) 10-dimensional measure of memory experience, and Boyacioglu and Akfirat's (2015) 14-dimensional measure of autobiographical memory characteristics. However, these memory scales comprise some dimensions (e.g., field perspective, observer perspective) that are not fully applicable to tourism contexts (Potheegadoo et al. 2013). Also, these scales tend to be overly lengthy or inadequate for testing complex models (Boyacioglu and Akfirat 2015; Luchetti and Sutin 2016). Existing scales are effective tools to investigate a specific event in that they guide respondents to evaluate a memory of an event (Boyacioglu and Akfirat 2015; Jorgenson et al. 2019; Luchetti and Sutin 2016). However, it should be noted that tourism experiences can be recollected and assessed based on information derived from multiple events and activities during a trip (H. Kim and Chen 2021). Therefore, a parsimonious type of memory scale is necessary in order to capture the key features of tourism experiences.

Studies in cognitive psychology have provided solid theoretical foundations to integrating memory phenomenology into tourism (Boyacioglu and Akfirat 2015; Sutin and Robins 2007). However, despite the acknowledgment of the significance of memory in tourism experience, there is a lack of research in the tourism literature related to memory phenomenology and there is a need for a measurement tool that can effectively capture various aspects of tourism memory. Jorgenson et al. (2019) developed the Tourism Autobiographical Memory Scale (TAMS) that 
consists of two dimensions: rehearsal and impact. Jorgenson et al.'s (2019) work established the foundation of tourism autobiographical memory. According to Rubin, Schrauf, and Greenberg (2003), the phenomenological features of information making up autobiographical memory can be understood considering recollection, sensory elements, emotion, and so forth. However, the TAMS covers a limited range of dimensions in spite of the multifaceted features of autobiographical memory. For example, some memory components that can be conceptually distinguished were merged into the dimension of rehearsal (Jorgenson et al. 2019). Therefore, to address this gap in the tourism literature, the present study attempts to consolidate the foundation of tourism memory by achieving three research objectives: firstly, to identify potential memory dimensions that can best explicate a tourism perspective; secondly, to develop a tourism memory characteristics scale (TMCS) that can be applied to general tourism contexts; and lastly, to identify the relationship between tourism memory and behavioral intentions to demonstrate the nomological validity of the newly developed TMCS.

The key theoretical contribution of the current study is to connect memory phenomenology from cognitive psychology with the tourism experience literature in order to develop a measurement tool for measuring the phenomenological characteristics of tourism memory. Thus, this study is expected to provide greater insights into tourism memory research. From a practical perspective, this new measurement tool will enable destination marketing organizations and tourism service providers to measure and understand major features of their products in the post-trip stage and facilitate further product developments.

\section{Theoretical Background}

\section{Autobiographical Memory}

Remembering events is an essential human process. In particular, memories associated with the self of one's past are collectively described as autobiographical memory. Fivush (2011, p. 560) defined autobiographical memory as "a uniquely human form of memory that moves beyond recall of experienced events to integrate perspective, interpretation, and evaluation across self, other, and time to create a personal history." Autobiographical memory formation includes features of episodic memory and semantic memory (Conway 2005; Piolino et al. 2002; Schwartz 2011; Tulving et al. 1988). Episodic memory entails a system used to encode, store, and retrieve past events and episodes involving personal experiences (Schwartz 2011; Tulving 1972). Many researchers have identified the key characteristic of episodic memory as recollection, which leads individuals to relive and reexperience an original event in memory (Rubin, Schrauf, and Greenberg 2003). By contrast, semantic memory is associated with a memory system that encodes, stores, and retrieves explicit information such as facts, ideas, concepts, and knowledge of the world (Schwartz 2011; Tulving 1972). Semantic aspects of autobiographical memory focus on personal, factual, or self-referent semantic knowledge, such as the name of "your family's holiday place when you were 12" (Meesters et al. 2000, p. 37). This semantic knowledge thus pertains to self-related general information (Tulving et al. 1988), distinguishing it from episodic components that contain memories of personally experienced events situated in time and place (Piolino et al. 2002).

Conway and Pleydell-Pearce (2000) proposed the SelfMemory System (SMS), which emphasizes the importance of self and long-term memory knowledge. The premise behind the SMS is that specific autobiographical memories form when the working self and autobiographical knowledge base are properly engaged (Conway and Pleydell-Pearce 2000). The working self refers to "the complex set of active goals and associated self-image" (Conway 2005, p. 594). Conway and Pleydell-Pearce (2000) suggested that autobiographical knowledge assumes a hierarchical structure in the SMS; that is, autobiographical memory involves 
knowledge distinguished by three levels of specificity. An individual follows a top-down process to retrieve this knowledge beginning from a lifetime period, general events, and finally event-specific knowledge (Conway 2005; Conway and Pleydell-Pearce 2000). The highest level encompasses lifetime periods that include general knowledge of activities, common locations, actions, feelings, plans, people, and goals common to a given period (Conway and Pleydell-Pearce 2000; Conway and Williams 2008). Individuals can access a particular period at this level, such as when I was a university sophomore. The next level of autobiographical knowledge base contains a category of general events that are more specific and heterogeneous compared with lifetime periods. General events are related to a set of affiliated events, involving a series of memories linked by a theme. Thus, general events include single occurrences (e.g., a trip to Paris) and repeated events (e.g., evening hikes in a meadow) (Conway and Pleydell-Pearce 2000). The last level of autobiographical knowledge base includes event-specific knowledge - vividly detailed information about personal events, such as visual images and sensory-perceptual knowledge (Conway and Pleydell-Pearce 2000). For example, "when remembering a honeymoon in Hawaii, you might still remember the optical image of the beach in front of the hotel where you stayed, many activity programmes you enjoyed in detail, and the romantic music you heard at the hotel lobby" (H. Kim and Chen 2021, p. 3). Essentially, conceptual and generic knowledge and event-specific knowledge are interlinked and activated together to inspire specific autobiographical memories (Conway 2005; Conway and Williams 2008).

Autobiographical memories can evoke emotions associated with one's original experiences (Speer, Bhanji, and Delgado 2014). It is thus worthwhile to further explore emotional memory to clarify the impact of autobiographical memory; indeed, individuals' future behavior is strongly influenced by experienced events tied to positive or negative memories (Speer and Delgado 2019; Watson et al. 2012; Wirtz et al. 2003). For example, Speer, Bhanji, and Delgado (2014) focused on the association between cognitive and emotional processes and found that positive autobiographical memories (e.g., a family vacation) engaged reward-related neural circuitry such as the striatum and medial prefrontal cortex. Watson et al. (2012) noted that recalling autobiographical memories can evoke a positive mood and corresponding physical reactions (e.g., talking with others, smiling).

A notable benefit of autobiographical memories is the social function of these memories. People build social bonds by sharing memories with others for persuasion and communication purposes (Bluck et al. 2005). The social function of autobiographical memory enables a person to initiate, develop, sustain, and enhance social bonds (Alea and Bluck 2003; Bluck and Alea 2011). As such, autobiographical memories harken back to moments of a particular time containing specific episodes, generic knowledge, sensory details, emotions, feelings, and narratives (Conway 2005; Rasmussen and Berntsen 2009; Speer, Bhanji, and Delgado 2014; Sutin and Robins 2007).

\section{Existing Measurement Scales of Memory}

Researchers have identified various phenomenological characteristics of memory. Sutin and Robins (2007) argued that memories generate intense phenomenological experiences. In fact, personally important memories can be described as phenomenological: they are vivid, affectively intense, and lead individuals to relive any experience that can be consciously remembered (Boyacioglu and Akfirat 2015; Sutin and Robins 2007; Tulving 2002).

In the memory literature, scholars have used memory to distinguish real and imagined events (Johnson et al. 1988). For example, Johnson et al. (1988) developed the Memory Characteristic Questionnaire to measure the phenomenology of memory in terms of vividness, sensory details, the intensity of feelings, thoughts, place details, and time details. Rubin, Schrauf, and Greenberg (2003) developed the Autobiographical Memory Questionnaire to 
assess judgments of recollection and belief (e.g., reliving, remembering/knowing, real/imagined), reported properties (e.g., importance, rehearsal, memory age), and component processes (e.g., sensory details, stories, emotions). However, memory researchers have continued to call for a psychometrically comprehensive and valid measure of autobiographical memory phenomenology (Boyacioglu and Akfirat 2015; Sutin and Robins 2007).

To address the limitations of available memory scales, Sutin and Robins (2007) developed the Memory Experiences Questionnaire (MEQ) with an eye toward reliability, validity, and comprehensiveness. The measure includes 63 items covering 10 phenomenological dimensions: accessibility, time details, vividness, emotional intensity, valence, sharing, distancing, visual perspective, sensory details, and coherence. The MEQ has been adopted to explore early childhood memories and self-defining (meaningful) memories. In such work, investigators instructed participants to recall a memory and describe the memory contents before completing the questionnaire. People's autobiographical memories generally contain fine-grained distinctions because personal memories vary even in identical circumstances. Thus, examining individuals' experiential memory contents and the intensity or frequency of the autobiographical memory phenomenology could help to contextualize specific autobiographical memories (Boyacioglu and Akfirat 2015; Sutin and Robins 2007).

Despite the original scale's utility, abbreviated versions of the MEQ have been applied to prevent participants from experiencing fatigue when completing all 63 items (Luchetti and Sutin 2016). A short form of the MEQ (MEQ-SF) was developed to reduce the original MEQ to 31 items while maintaining the same 10 dimensions (Luchetti and Sutin 2016). Boyacioglu and Akfirat (2015) pointed out other limitations of the MEQ; for example, several key phenomenological characteristics of autobiographical memory (e.g., recollection and place details) are neglected. Boyacioglu and Akfirat (2015) then created the Autobiographical Memory Characteristics Questionnaire (AMCQ) to address the theoretical and practical limitations of existing scales. They defined autobiographical memory as a type of memory associated with important events (e.g., school life, family life, romantic relationships) that an individual has personally experienced. The AMCQ contains 63 items and 14 dimensions: vividness, preoccupied with emotion, emotional valence, accessibility, field perspective, observer perspective, place details, recollection, sharing, emotional distancing, sensory details, emotional intensity, narrative coherence, and belief in accuracy. In spite of its comprehensiveness, the AMCQ is a lengthy instrument, thus increasing the burden on respondents. In addition to practical constraints, an extensive scale often depends on data valuation rather than theory, suggesting that brief scale versions can be more rigorous for theory testing (Boley et al. 2021; Ribeiro et al. 2018; Ziegler, Kemper, and Kruyen 2014).

Given the importance of autobiographical memory phenomenology, an increasing number of tourism studies have also paid attention to the autobiographical memory phenomenology of tourism experiences (Jorgenson et al. 2019; H. Kim and Chen 2021).

\section{Tourism Memory and Measurement}

In the post-trip stage, tourism experiences can be referred to as memories (Larsen 2007) that involve a variety of sensory elements (Agapito, Pinto, and Mendes 2017), emotional contents (Rahmani, Gnoth, and Mather 2019), and narratives (Jepson, Stadler, and Spencer 2019). Especially, long-term memory is crucial for understanding and defining tourism experiences (J. H. Kim, Ritchie, and McCormick 2012; Larsen 2007; Pearce and Packer 2013). Tung and Ritchie (2011a, p. 1369) defined tourism experiences as "an individual's subjective evaluation and undergoing (i.e., affective, cognitive, and behavioral) of events related to his or her tourist activities which begin before (i.e., planning and preparation), during (i.e., at the destination), and after the trip (i.e., recollection)." In the context of autobiographical memory, individuals can remember what happened to them (Fivush 2011). Research on memorable tourism 
experience (MTE) has covered this essence of tourism-related memory by requiring respondents to recall MTEs of one's past (J. H. Kim 2010; J. H. Kim, Ritchie, and McCormick 2012). H. Kim and Chen (2019) have further advanced an understanding of MTE and their link to autobiographical memory by investigating the relationship between MTE and travel reminiscence functions (i.e., directive function, self function, and social function).

Tourism studies have started to look at the phenomenology of autobiographical memory (H. Kim and Chen 2021) that helps to understand the complex interaction among cognitiveaffective-behavioral aspects of tourism memory (Tung and Ritchie 2011a). For example, Jorgenson et al. (2019) developed a tourism autobiographical memory scale (TAMS) to assess visitors' experiences based on autobiographical memories. The TAMS revealed two dimensions: rehearsal (talk about the memory, think about the memory, write about the memory, emotional imagery, emotional intensity) and impact ("comes to me in words/pictures," significance, consequences). However, despite its contribution in building a theoretical basis of tourism autobiographical memory (Jorgenson et al. 2019), the TAMS did not cover several primary phenomenological dimensions that are essential to unearthing autobiographical memories, such as place details, vividness, and sensory details.

In the psychology literature, a comprehensive set of memory dimensions was identified by Sutin and Robins (2007) and Boyacioglu and Akfirat (2015). Nonetheless, their frameworks are overly complex, including memory dimensions that may be not appropriate or applicable to explain tourism-related memory and its associated phenomena such as behavioral intentions. Existing memory scales are appropriate for measuring a single event that enables respondents to access a specific memory in that they used the words "this event" in the scale items (Boyacioglu and Akfirat 2015; Sutin and Robins 2007; Jorgenson et al. 2019; Luchetti and Sutin 2016). Their ways of measuring memories are not always applicable to tourism contexts because a tourism trip often involves multiple events and activities (H. Kim and Chen 2021) that take place in several locations (Marschall 2014) and time (Weaver, Weber, and McCleary 2007). General terms such as tourism experiences, a trip, and a destination are often used to instruct respondents to recall memories, which allow them to utilize various information for an evaluation of their experiences (Agapito, Pinto, and Mendes 2017; J. H. Kim 2020; H. Kim and Chen 2019). Given the shortcomings of existing measures of autobiographical memory, a more robust tourism memory scale needs to be developed to better capture the phenomenological characteristics of tourism memory.

\section{Potential Dimensions of Tourism Memory Characteristics}

Based on previous memory scales (Boyacioglu and Akfirat 2015; Sutin and Robins 2007; Jorgenson et al. 2019; Luchetti and Sutin 2016) and the weaknesses and limitations associated with previous tourism memory scales, this study selected the most relevant dimensions that could best explicate the nuances of tourism-related autobiographical memories: Accessibility, Time Details, Place Details, Recollection, Sensory Details, Vividness, Emotional Intensity, Positive Valence, Negative Valence, Sharing.

Accessibility. Accessibility is one of the central properties to understand individuals' ability to mentally access their memory, regarding the ease of memory retrieval (Sutin and Robins 2007) and cognitive rehearsal (i.e., thinking) (Boyacioglu and Akfirat 2015). Within tourism, accessibility has been investigated using sensory cues (J. H. Kim and Jang 2016), a destination's products (Yin, Poon, and Su 2017), and visitor experiences (Jorgenson et al. 2019). Furthermore, Jorgenson et al. (2019) evaluated how frequently a person has thought about the memory of the trip-related events and found that cognitive rehearsal is a key component of tourism autobiographical memory.

Time Details and Place Details. Time details refer to clarity of memory relating to the time 
when an experience occurred (Sutin and Robins 2007), while place details refer to clarity of memory concerning a place where the experience occurred (Boyacioglu and Akfirat 2015). When accessing memories of tourism experiences, individuals' perceptions of general information such as place (J. H. Kim 2014) and time (Tung and Ritchie 2011b) vary. For example, Marschall (2014) asked participants to recall travel patterns from their childhood and memories of remembered trips. Findings revealed that participants revisited the sites and destinations derived from important personal memories associated with childhood, prior holidays, or their honeymoon.

Recollection. Recollection can be described as a sense of reliving the original event during the recalling process (Boyacioglu and Akfirat 2015; Rubin, Schrauf, and Greenberg 2003). In the post-trip stage, tourism experiences in which individuals personally participated can become an important source of information that helps recollect tourism-related memories (J. H. Kim 2010; H. Kim and Chen 2021; J. H. Kim and Jang 2016).

Sensory Details. Sensory details refer to those reexperienced during retrieval of events that involves visual, tactile, olfactory, and auditory details as well as body position (Boyacioglu and Akfirat 2015). Sensory details are considered a core feature of tourism experiences, going beyond mere interaction with one's environment or surroundings because post-travel multisensory impressions can imprint on memory (Agapito, Pinto, and Mendes 2017; Ballantyne, Packer, and Sutherland 2011). Tourism researchers have emphasized five senses (i.e., sight, hearing, smell, taste, and touch) (Agapito, Pinto, and Mendes 2017) and bodily feelings (Lv, Li, and McCabe 2020) to understand how each sensory impression contributes to long-term memory and tourists' future behavior.

Vividness. The MEQ differentiates visual clarity (i.e., vividness) from other sensory details as vividness is pivotal to predicting the strength of recollection (Sutin and Robins 2007; Rubin 2005). For instance, some visual images formed during a trip are vividly remembered after a few decades (Anderson and Shimizu 2007) or a few months (Ballantyne, Packer, and Sutherland 2011) since the event occurred. Agapito, Pinto, and Mendes (2017) found that respondents tend to have fewer diverse visual impressions, with certain visual elements leaving stronger sensory impressions as time passed.

Emotional Intensity. Emotional intensity refers to "the intensity of the emotions experienced both at the time of encoding and at the time of retrieval" (Sutin and Robins 2007, p. 394). Emotions embedded in tourism memory interact not only with emotional contents but also with a motivational resource that triggers a desire to travel (Prayag, Hosany, and Odeh 2013; Rahmani, Gnoth, and Mather 2019). Jorgenson et al. (2019) further discovered that recall of visitors' experiences evokes emotions of original experiences during the retrieval.

Valence. Valence refers to "the degree to which the experience described in the memory is perceived to be positive or negative" (Sutin and Robins 2007, p. 394). Earlier MTE studies have focused on positive valence in describing the MTE (J. H. Kim, Ritchie, and McCormick 2012; Tung and Ritchie 2011a). Yet recent tourism memory researchers have focused on negative memory, pointing out that tourism experience studies highly rely on positively remembered experiences despite the significance of negative memory in managing and marketing destinations (J. H. Kim 2020). Accordingly, the present study considers positive valence and negative valence as distinct dimensions.

Sharing. Sharing refers to "the extent to which the memory is shared with other people" (Sutin and Robins 2007, p. 394). Tourism memories can be frequently shared for social communication (Jorgenson et al. 2019). In previous research, sharing and discussing memories were found to boost travelers' positive affect (J. Kim and Fesenmaier 2017) and the quality of life (Jepson, Stadler, and Spencer 2019). 
Based on an extensive review of the tourism literature, 10 phenomenological characteristics of tourism memory were specified to develop a more thorough scale of tourism memory (see Table 1). There is sufficient evidence that tourism memories closely intersect with tourism experiences, capturing autobiographical knowledge in the Self-Memory System (Conway 2005; Conway and Pleydell-Pearce 2000) as well as the social function of autobiographical memory (Bluck et al. 2005). Following Boyacioglu and Akfirat's (2015) definition of autobiographical memory, we define tourism memory in this study as a form of memory associated with important tourism experiences in which an individual was personally involved.

\section{Tourism Memory and Behavior}

Tourism-related memories can permeate travelers' decision-making process because personally experienced events are first recalled based on accessible information and then evaluated to guide future behavior (H. Kim and Chen 2019; Tung and Ritchie 2011a; Yin, Poon, and Su 2017). H. Kim and Chen (2019) found that travel reminiscence functions can predict tourists' behavior. In particular, the directive reminiscence function enables individuals to make timely decisions when choosing a future destination. Furthermore, the authors highly valued the social reminiscence function because it leads individuals to share tourism memories with others to establish or promote social bonds. Tourism studies have investigated past behavior by soliciting the frequency of travelers' prior visits to a destination (Jorgenson et al. 2019) and the frequency of memory sharing (Jepson, Stadler, and Spencer 2019). Furthermore, many tourism researchers have focused on whether the experiences derived from tourism memories continuously affect travelers' behavioral intentions, such as purchase intentions (Yin, Poon, and $\mathrm{Su}$ 2017), intentions to repeat the experience (Wirtz et al. 2003), and word-of-mouth (WOM) and revisit intentions (Agapito, Pinto, and Mendes 2017). Relatedly, a comprehensive investigation into the link between tourists' past behavior and behavioral intentions might more accurately predict the relationship between tourism memories and behavior.

With the defined research purposes in mind, the next step of this study focuses on proposing a scale of tourism memory characteristics by following scale development approaches recommended by Churchill (1979) and Hinkin (1995). Furthermore, the relationship between tourism memory and behavioral intentions is investigated to demonstrate the predictive power of the new scale for tourists' future behavior. 
Table 1. Potential Dimensions of Tourism Memory Characteristics Scale

\begin{tabular}{|c|c|c|c|c|c|c|c|}
\hline Authors/Year & Vividness & Accessibility & $\begin{array}{l}\text { Sensory } \\
\text { Details }\end{array}$ & $\begin{array}{l}\text { Emotional } \\
\text { Intensity }\end{array}$ & $\begin{array}{l}\text { Positive } \\
\text { Valence }\end{array}$ & $\begin{array}{l}\text { Negative } \\
\text { Valence }\end{array}$ & $\begin{array}{l}\text { Time } \\
\text { Details }\end{array}$ \\
\hline \multicolumn{8}{|l|}{$\begin{array}{c}\text { Jepson et al. (2019); Kim and } \\
\text { Fesenmaier (2017) }\end{array}$} \\
\hline Anderson and Shimizu (2007) & $\star$ & & & & & & \\
\hline Jorgenson et al. (2019) & & $\star$ & & $\star$ & & & \\
\hline $\begin{array}{c}\text { Kim et al. (2012); Tung and } \\
\text { Ritchie (2011a) }\end{array}$ & & & & & $\star$ & & \\
\hline $\operatorname{Kim}(2020)$ & & & & & & $\star$ & \\
\hline Yin et al. (2017) & & $\star$ & & & & & \\
\hline $\begin{array}{l}\text { Ballantyne et al. (2011); Lv et } \\
\text { al. (2020); Agapito et al. (2017) }\end{array}$ & $\star$ & & $\star$ & & & & \\
\hline $\begin{array}{c}\text { Prayag et al. (2013); Wirtz et } \\
\text { al. (2003) }\end{array}$ & & & & $\star$ & & & \\
\hline Speer et al. (2014) & & & & $\star$ & $\star$ & & \\
\hline $\begin{array}{l}\text { Kim (2010); Kim and Jang } \\
\text { (2016); Kim and Youn (2017) } \\
\text { Kim (2014) }\end{array}$ & $\star$ & & $\star$ & & & & \\
\hline Tung and Ritchie (2011b) & & & & & & & $\star$ \\
\hline Marschall (2014) & & & & & & & $\star$ \\
\hline
\end{tabular}




\section{Methodology}

\section{Scale Development and Validation}

This study sought to develop the Tourism Memory Characteristics Scale (TMCS) to measure the phenomenological characteristics of tourism memory. To achieve this purpose, a deductive scale development procedure was adopted (Churchill 1979; DeVellis 2016; Hinkin 1995). Churchill's (1979) steps have been adopted in earlier scale development studies and represent the gold standard of tourism scale creation (Boley and McGehee 2014). Each step of this scale development procedure, including associated methods, samples, and results, is summarized in Table 2.

Table 2. Scale Development Procedures

\begin{tabular}{|c|c|c|c|}
\hline & Procedure & Method/Sample & Findings \\
\hline 1 & $\begin{array}{l}\text { Specify the domain of } \\
\text { the construct }\end{array}$ & $\begin{array}{l}\text { Literature review } \\
\text { - experience and memory } \\
\text { - pre-existing scales } \\
\text { - define construct }\end{array}$ & 10 potential dimensions \\
\hline 2 & $\begin{array}{l}\text { Generate a pool of } \\
\text { items and refine the } \\
\text { items }\end{array}$ & $\begin{array}{l}\text { Deductive approaches } \\
\text { - literature review on experience and memory } \\
\text { - four pre-existing scales }\end{array}$ & 49 items, 10 dimensions \\
\hline & & $\begin{array}{l}\text { Item refinement } \\
\text { - content validity: experts }(N=24) \\
\text { - pre-test with target audience }(N=121)\end{array}$ & 51 items, 10 dimensions \\
\hline 3 & $\begin{array}{l}\text { Collect data for a pilot } \\
\text { study }\end{array}$ & $\begin{array}{l}\text { Pilot test }(N=355) \\
\text { - survey: online }\end{array}$ & \\
\hline 4 & Purify measure & EFA and Cronbach's alpha reliability test & 33 items, 7 dimensions \\
\hline 5 & $\begin{array}{l}\text { Data collection for the } \\
\text { main study }\end{array}$ & $\begin{array}{l}\text { Main study }(N=351) \\
\text { - survey: online }\end{array}$ & \\
\hline 6 & $\begin{array}{l}\text { Assess validity and } \\
\text { reliability }\end{array}$ & $\begin{array}{l}\text { CFA } \\
\text { - convergent validity, discriminant validity, } \\
\text { construct reliability } \\
\text { Pearson correlation } \\
\text { - nomological validity } \\
\text { PLS-SEM } \\
\text { - predictive validity }\end{array}$ & 26 items, 7 dimensions \\
\hline 7 & Develop norm & Future research & $\begin{array}{l}\text { Need to further validate } \\
\text { TMCS }\end{array}$ \\
\hline
\end{tabular}

Note: $\mathrm{EFA}=$ exploratory factor analysis, $\mathrm{CFA}=$ confirmatory factor analysis, PLS-SEM = partial least square structural equation modelling.

\section{Step 1: Specifying Construct Domains}

As Churchill (1979) recommended, an extensive literature review was performed to determine what exactly to measure for scale development. This step was addressed through a review of literature on memory in psychology and tourism, preexisting scales, and tourism experiences. Based on the literature review, tourism memory was operationalized as a form of memory associated with important tourism experiences in which an individual was personally involved, including phenomenological characteristics of autobiographical memory. Furthermore, 10 potential TMCS dimensions were identified by considering the relevance of these constructs in a tourism context. By using the MEQ (Sutin and Robins 2007) and AMCQ (Boyacioglu and Akfirat 2015), the definitions of 10 TMCS dimensions were modified to represent a tourism perspective. The definitions in Table 3 were adopted to establish an initial pool of scale items. 
Table 3. Definition of Potential Dimensions

\begin{tabular}{|c|c|c|}
\hline Dimension & Definition & Reference \\
\hline Accessibility & An ability to mentally access tourism memory & $\begin{array}{l}\text { Boyacioglu and Akfirat (2015); } \\
\text { Sutin and Robins (2007); } \\
\text { Jorgenson et al. (2019); Yin et al. } \\
(2017)\end{array}$ \\
\hline Time details & $\begin{array}{l}\text { The clarity of tourism memory referring to the } \\
\text { time when an individual traveled }\end{array}$ & $\begin{array}{l}\text { Marschall (2014); Sutin and } \\
\text { Robins (2007); Tung and Ritchie } \\
\text { (2011b) }\end{array}$ \\
\hline Place details & $\begin{array}{l}\text { The clarity of tourism memory referring to } \\
\text { places where an individual traveled }\end{array}$ & $\begin{array}{l}\text { Boyacioglu and Akfirat (2015); } \\
\text { Kim (2014); Marschall (2014) }\end{array}$ \\
\hline Recollection & $\begin{array}{l}\text { A sense of reliving the specific trip in one's } \\
\text { mind }\end{array}$ & $\begin{array}{l}\text { Boyacioglu and Akfirat (2015); } \\
\text { Kim (2010); Kim and Youn (2017) }\end{array}$ \\
\hline Vividness & The visual clarity of tourism memory & $\begin{array}{l}\text { Anderson and Shimizu (2007); } \\
\text { Kim (2010); Rubin (2005); Sutin } \\
\text { and Robins (2007) }\end{array}$ \\
\hline Sensory details & $\begin{array}{l}\text { Sensory details re-experienced during the } \\
\text { retrieval of tourism memory }\end{array}$ & $\begin{array}{l}\text { Agapito et al. (2017); Ballantyne et } \\
\text { al. (2011); Boyacioglu and Akfirat } \\
\text { (2015); Lv et al. (2020); Sutin and } \\
\text { Robins (2007) }\end{array}$ \\
\hline Positive valence & $\begin{array}{l}\text { The extent to which tourism memory is } \\
\text { perceived to be positive }\end{array}$ & $\begin{array}{l}\text { Speer et al. (2014); Sutin and } \\
\text { Robins (2007); Kim et al. (2012) }\end{array}$ \\
\hline Negative valence & $\begin{array}{l}\text { The extent to which tourism memory is } \\
\text { perceived to be negative }\end{array}$ & $\begin{array}{l}\text { Kim (2020); Speer et al. (2014); } \\
\text { Sutin and Robins (2007) }\end{array}$ \\
\hline Emotional intensity & $\begin{array}{l}\text { The intensity of emotions experienced by an } \\
\text { individual concerning tourism memory }\end{array}$ & $\begin{array}{l}\text { Boyacioglu and Akfirat (2015); } \\
\text { Jorgenson et al. (2019); Speer et al. } \\
\text { (2014); Sutin and Robins (2007); } \\
\text { Prayag et al. (2013) }\end{array}$ \\
\hline Sharing & $\begin{array}{l}\text { The extent to which tourism memory is shared } \\
\text { with or to other people }\end{array}$ & $\begin{array}{l}\text { Jepson et al. (2019); Jorgenson et } \\
\text { al. (2019); Kim and Chen (2019); } \\
\text { Kim and Fesenmaier (2017); Sutin } \\
\text { and Robins (2007) }\end{array}$ \\
\hline
\end{tabular}

\section{Step 2: Generating and Refining Measurement Items}

The next step involved generating initial items to capture salient dimensions and their definitions as specified above (Carpenter 2018; Churchill 1979). Deductive scale development approaches were adopted that pertained to item generation rooted in a theoretical foundation and preexisting scales; these methods provided enough information to assemble an initial item pool (Boyacioglu and Akfirat 2015; Hinkin 1995; Jorgenson et al. 2019; Sutin and Robins 2007). At first, 49 items covering 10 constructs were created from the MEQ-SF (Luchetti and Sutin 2016), AMCQ (Boyacioglu and Akfirat 2015), and the tourism literature.

To evaluate content validity, the expert and target audience panels reviewed all items and constructs in May 2020. All material was sent to 24 experts in tourist behavior, consumer behavior, and scale development. The expert panel was given clear definitions of each construct and asked to evaluate construct deficiencies, items' representativeness of related construct domains using a five-point Likert-type scale $(1=$ not representative at all; $5=$ very representative), and the relevance of constructs and items to general tourism cases $(1=$ not relevant at all; $5=$ very relevant). Items with a mean value of 3 or higher were retained (Haynes, Richard, and Kubany 1995; Liu, Yao, and Fan 2020). All items were scored above the mean value of 3 in terms of representativeness and relevance. Additionally, the 24 experts were asked to provide suggestions to further refine the TMCS.

As suggested by Carpenter (2018), the expert panel's commentary was carefully reviewed and adopted to improve the TMCS. Five comments indicated concerns about the reverse-item bias because reversed polarity items are often problematic, reducing reliability and validity 
estimates (Boley, Jordan, and Woosnam 2020). Two remarks advised that each construct should contain at least four items. Indeed, Mowen and Voss (2008) recommended that if a scale includes dimensions, then each dimension should have three to five items for conceptual and pragmatic reasons. Two experts pointed out a double-barreled item in the recollection dimension. In line with experts' critiques, all generated items were positively reworded apart from accessibility following Boyacioglu and Akfirat's approach (2015). Five reverse-scored items were deleted because they had the same meaning as other items under the associated construct. Six items were further adapted from the MEQ (Sutin and Robins 2007) and TAMS (Jorgenson et al. 2019). One double-barreled item was divided into two items.

After refining the items in accordance with experts' comments, a pretest was conducted focusing on target audiences aged $\geq 18$ years. The full scale was pretested with 121 participants for further refinement. Participants were asked to indicate problematic items based on phrasing along with any challenges they encountered in understanding items' content. The nonexpert panel reported no problems understanding the TMCS. Ultimately, 51 items related to 10 dimensions were retained for the pilot study: vividness (6 items), sensory details (6 items), emotional intensity ( 5 items), positive valence (4 items), negative valence (4 items), time details (5 items), place details (4 items), recollection (6 items), sharing (6 items), and accessibility (5 items). Lastly, three experts in tourist behavior and scale development thoroughly reviewed all constructs and items and agreed to use the TMCS for a pilot study in May 2020.

\section{Step 3: Data Collection for Pilot Study}

After refining the initial item pool, participants were asked to complete the three-part questionnaire. The first part was designed to help respondents recall personal tourism experiences based on instructions to write down a memory about an important tourism experience. The tourism memory-writing directions were adapted from Sutin and Robins (2007) and Boyacioglu and Akfirat (2015). Respondents were instructed to recall any tourism experience regardless of trip type or the age at which they experienced the memory:

Please describe a memory about a tourism experience that you consider personally important and you were personally involved in. You can usually recall or trace the date of the memory. Please describe the memory in detail: what happened and whom you were with (if anyone), and how you felt or reacted.

The second part of the questionnaire consisted of items measuring the phenomenology of tourism memory (51 items). A 7-point Likert-type scale $(1=$ strongly disagree; $7=$ strongly agree) was applied to evaluate the phenomenology of tourism memory. The last section included choice questions on respondents' sociodemographic information, trip characteristics (i.e., destination type, number of past visits), and memory characteristics (i.e., age at which the trip was made). An online questionnaire was hosted on Qualtrics to collect data via Amazon Mechanical Turk (MTurk) using a detailed screening process recommended in previous research (Soulard, McGehee, and Knollenberg 2021).

Data cleaning was performed to eliminate questionnaires with missing data and careless response patterns. Carelessness was identified based on whether respondents correctly answered three of the instructed response items and the attention check question (e.g., "This is an attention check question: Please select strongly disagree"). Questionnaires from respondents who failed the attention check questions and who completed the survey too quickly were eliminated from the sample (Soulard, McGehee, and Knollenberg 2021). The appropriate sample size was determined in line with Netemeyer, Bearden, and Sharma (2003) and 
Worthington and Whittaker (2006), who suggested a sample of 300 respondents for a largescale pilot study. Following these recommendations, the pilot study questionnaire gathered data from American participants in May 2020.

\section{Results}

\section{Step 4: Purifying the Measures}

Data analyses for TMCS purification followed a stepwise approach adopted by many researchers (Boley and McGehee 2014). To purify the measure, the pilot study sample $(N=$ 355) was subjected to exploratory factor analysis (EFA) via principal axis factoring with Promax to identify the underlying dimensionality of tourism memory (Otoo, Kim, and Choi 2021; Soulard, McGehee, and Knollenberg 2021). The following cut-off values were adopted: Kaiser-Meyer-Olkin (KMO) values greater than 0.60 , eigenvalues greater than 1.0, communalities greater than 0.50 , and factor loadings greater than 0.40 or cross-loadings less than 0.40 (Hair et al. 2019). After EFA, internal consistency reliability was examined using the identified factors. Items were retained if they exhibited item-to-total correlations greater than 0.50 and Cronbach's alpha values greater than 0.70 (Hair et al. 2019).

Several rounds of EFA led to 18 items being dropped, including 7 items with low communalities, 6 items that were conceptually unrelated to the corresponding component, 4 items with high cross-loadings, and 1 item with a low factor loading. As a result, two dimensions (i.e., recollection and negative valence) were dropped mainly due to cross-loadings and items loaded onto conceptually unrelated factors. Time details and place details were identified as the same factor. Thus, 33 items covering seven dimensions remained.

The final EFA was performed with the remaining 33 items. The KMO measure of sampling adequacy (0.914) and Bartlett's test of sphericity $\left(\chi^{2}=8619.372, d f=528, p<0.001\right)$ demonstrated the adequacy of the pilot data for EFA (Tabachnick and Fidell 2013). As presented in Table 4, seven factors had eigenvalues greater than 1, and all items met the criterion for commonality $(>0.50)$ and loaded on related factors; factor loadings ranged from 0.51 to 0.90 . Item-total correlations ranged from 0.60 to 0.84 , and all Cronbach's alphas exceeded 0.70 , reflecting a high level of internal consistency or reliability (Tabachnick and Fidell 2013). EFA resulted in 33 items related to seven dimensions being retained and labeled. Six factors were labeled based on prior memory research, and one factor was renamed by combining time details and place details into "trip details." These seven items explained 73.64\% of the total variance. The refined scale was deemed appropriate for further scale development and validity assessment. 
Table 4. Exploratory Factor Analysis Result for the Pilot Study $(N=355)$

\begin{tabular}{|c|c|c|c|c|}
\hline Construct and Item & $\begin{array}{l}\text { Factor } \\
\text { Loading }\end{array}$ & $\begin{array}{l}\text { Item to Total } \\
\text { Correlation }\end{array}$ & Eigenvalue & $\begin{array}{l}\text { Variance } \\
\text { Explained }\end{array}$ \\
\hline Accessibility $(\alpha=0.92)$ & & & 11.16 & $35.34 \%$ \\
\hline $\begin{array}{l}\text { I had to think for a while before I could recall this trip } \\
\text { (R). }\end{array}$ & 0.89 & 0.82 & & \\
\hline I had to search my memory to recall this trip (R). & 0.88 & 0.83 & & \\
\hline I do not recall this trip very often $(\mathrm{R})$. & 0.84 & 0.75 & & \\
\hline $\begin{array}{l}\text { Since it happened, I have not thought about this trip very } \\
\text { often (R). }\end{array}$ & 0.80 & 0.75 & & \\
\hline It was difficult for me to think of this memory (R). & 0.77 & 0.80 & & \\
\hline Trip Details $(\alpha=0.88)$ & & & 4.77 & $14.47 \%$ \\
\hline My memory for the region(s) where I traveled is clear. & 0.62 & 0.69 & & \\
\hline My memory for the city(ies) where I traveled is clear. & 0.68 & 0.74 & & \\
\hline $\begin{array}{l}\text { My memory for the destination(s) where I traveled is } \\
\text { clear. }\end{array}$ & 0.51 & 0.66 & & \\
\hline My memory for the year when I traveled is clear. & 0.84 & 0.73 & & \\
\hline My memory for the month(s) when I traveled is clear. & 0.79 & 0.66 & & \\
\hline My memory for the season when I traveled is clear. & 0.79 & 0.74 & & \\
\hline Emotional Intensity $(\alpha=0.91)$ & & & 2.23 & $6.77 \%$ \\
\hline This memory evokes powerful emotions. & 0.86 & 0.81 & & \\
\hline This memory evokes strong emotions in me. & 0.83 & 0.81 & & \\
\hline My emotions are very intense concerning this trip. & 0.81 & 0.77 & & \\
\hline $\begin{array}{l}\text { While remembering this trip now, my feelings are very } \\
\text { intense. }\end{array}$ & 0.67 & 0.76 & & \\
\hline $\begin{array}{l}\text { I remember having particularly strong emotions at the } \\
\text { time of this trip. }\end{array}$ & 0.80 & 0.73 & & \\
\hline Sharing $(\alpha=0.92)$ & & & 1.82 & $5.54 \%$ \\
\hline I often talk about this trip with my friends or family. & 0.88 & 0.82 & & \\
\hline I frequently tell others about this memory. & 0.87 & 0.84 & & \\
\hline I frequently talk about this trip with others. & 0.86 & 0.84 & & \\
\hline I often share this memory with others. & 0.86 & 0.80 & & \\
\hline Valence $(\alpha=0.90)$ & & & 1.44 & $4.39 \%$ \\
\hline The overall tone of this memory is quite positive. & 0.90 & 0.84 & & \\
\hline My feelings at the time were quite positive. & 0.85 & 0.79 & & \\
\hline My overall feeling about this trip is quite positive. & 0.68 & 0.71 & & \\
\hline The experience described in this memory is positive. & 0.88 & 0.80 & & \\
\hline Sensory Details $(\alpha=0.83)$ & & & 1.34 & $4.07 \%$ \\
\hline $\begin{array}{l}\text { When I recall this memory, I can smell in my mind the } \\
\text { things that I smelled during the trip. }\end{array}$ & 0.79 & 0.68 & & \\
\hline $\begin{array}{l}\text { When I recall this memory, I can remember tactile } \\
\text { details related to the trip. }\end{array}$ & 0.76 & 0.65 & & \\
\hline $\begin{array}{l}\text { When I recall this memory, I can hear in my mind the } \\
\text { sounds that I heard during the trip. }\end{array}$ & 0.67 & 0.68 & & \\
\hline $\begin{array}{l}\text { When I recall this memory, I can feel the bodily } \\
\text { sensation that I felt during the trip. }\end{array}$ & 0.63 & 0.64 & & \\
\hline Vividness $(\alpha=0.86)$ & & & 1.01 & $3.06 \%$ \\
\hline My memory for this trip is very vivid. & 0.74 & 0.70 & & \\
\hline My memory for this trip is very clear. & 0.70 & 0.71 & & \\
\hline My memory for this trip is very detailed. & 0.63 & 0.70 & & \\
\hline $\begin{array}{l}\text { I can remember the situation in this trip vividly as if I } \\
\text { was there. }\end{array}$ & 0.59 & 0.71 & & \\
\hline $\begin{array}{l}\text { If asked, I could make a film about this trip that would } \\
\text { depict exactly what happened. }\end{array}$ & 0.56 & 0.60 & & \\
\hline Total variance explained & & & & $73.64 \%$ \\
\hline
\end{tabular}

Note: $\alpha=$ Cronbach's alpha; $(\mathrm{R})=$ Reversed items.

\section{Step 5: Data Collection for Main Study}

Following the pilot study, the main study was performed to validate the TMCS (33 items covering seven dimensions) by testing the scale's reliability, convergent validity, and 
discriminant validity. Revisit intention ( 3 items) and WOM (3 items) scales were added to the questionnaire (Papadimitriou, Kaplanidou, and Apostolopoulou 2018; Ribeiro et al. 2018; Um, Chon, and Ro 2006) to evaluate nomological and predictive validity of TMCS. Similar to the pilot study, all items were scored on a 7-point Likert-type scale ranging from $1=$ strongly disagree to $7=$ strongly agree. Also, as in the pilot survey, sociodemographic variables were added to the questionnaire to profile the respondents more effectively. Data were collected from American participants in June 2020 via Amazon MTurk. The study included respondents older than 18 years. Those who did not describe tourism memory were excluded after reviewing the written contents. The same survey administrative procedure was applied in the pilot study and the main study. After data cleaning, 351 valid survey responses were retained for analysis.

\section{Sociodemographic Profile of Main Study Respondents}

Table 5 lists the main study respondents' sociodemographic profile. Male participants $(56.7 \%)$ outnumbered their female counterparts (43.3\%). Respondents ranged in age from 18-30 (25.5\%), 30-39 (35.9\%), 40-49 (24.5\%), 50-59 (9.0\%), and above 60 years old (5.1\%). Most respondents $(63.5 \%)$ possessed a college/university degree. The vast majority were either married/living with a partner $(67.8 \%)$ or single (26.2\%). In terms of destination types, $57.5 \%$ of respondents recalled memories about a domestic trip, while $42.5 \%$ of them indicated that their memories were associated with an international trip. Slightly less than half of respondents $(45 \%)$ stated that they had visited the destination once, whereas $55 \%$ of them indicated they revisited the same destination over time. As for memory age, most respondents had experienced the recalled events less than 5 years ago $(58.0 \%)$.

Table 5. Sociodemographic Profile of the Main Study $(N=351)$

\begin{tabular}{|c|c|c|c|}
\hline Variables & Category & Frequency & Percentage \\
\hline \multirow[t]{2}{*}{ Gender } & Male & 199 & 56.7 \\
\hline & Female & 152 & 43.3 \\
\hline \multirow[t]{5}{*}{ Age } & $18-29$ & 90 & 25.5 \\
\hline & $30-39$ & 126 & 35.9 \\
\hline & $40-49$ & 86 & 24.5 \\
\hline & $50-59$ & 32 & 9.0 \\
\hline & $\geq 60$ & 17 & 5.1 \\
\hline \multirow[t]{3}{*}{ Education } & High school or lower & 41 & 11.7 \\
\hline & College/University degree & 223 & 63.5 \\
\hline & Postgraduate degree & 87 & 24.8 \\
\hline \multirow[t]{4}{*}{ Marital Status } & Married/living with a partner & 238 & 67.8 \\
\hline & Single & 92 & 26.2 \\
\hline & Divorced/separated & 18 & 5.1 \\
\hline & Widowed & 3 & 0.9 \\
\hline \multirow[t]{2}{*}{ Type of Destination } & Domestic trip & 202 & 57.5 \\
\hline & International trip & 149 & 42.5 \\
\hline \multirow[t]{6}{*}{ Number of Past Visit } & 1 & 158 & 45.0 \\
\hline & 2 & 61 & 17.4 \\
\hline & 3 & 43 & 12.3 \\
\hline & 4 & 22 & 6.3 \\
\hline & 5 & 21 & 6.0 \\
\hline & $>6$ & 46 & 13.0 \\
\hline \multirow[t]{5}{*}{ Memory Age (Year) } & $<5$ & 202 & 58.0 \\
\hline & $6-10$ & 64 & 18.0 \\
\hline & $11-15$ & 29 & 8.0 \\
\hline & $16-20$ & 23 & 7.0 \\
\hline & $>21$ & 33 & 9.0 \\
\hline
\end{tabular}

Step 6: Validation of TMCS through Confirmatory Factor Analysis

The validity and reliability of the TMCS were evaluated next. Confirmatory factor analysis 
(CFA) was performed to analyze the measurement model and confirm the seven dimensions extracted from EFA by assessing model fit indices, convergent validity, and discriminant validity. CFA was performed with the main sample in IBM AMOS v27 (Arbuckle 2016) along with maximum likelihood estimation (ML). The overall fit of the measurement model was determined by multiple goodness-of-fit indices based on recommended cut-off values (Hu and Bentler 1999; Kline 2016), such as the root mean square error of approximation (RMSEA $\leq$ 0.08 ), standardized root mean square residual (SRMR $\leq 0.08)$, Tucker-Lewis index (TLI $\geq$ $0.90)$, and comparative fit index (CFI $\geq 0.90)$. The parsimony of the model fit was assessed using the Akaike information criterion (AIC; Akaike 1987) and Browne-Cudeck criterion (BCC; Browne and Cudeck 1989). Lower AIC and BCC values convey a better model fit (Hu and Bentler 1995). Initial fit indices of the seven-dimension first-order CFA model demonstrated an acceptable model fit: $\chi^{2}=1084.96, d f=473, p<0.001, \chi^{2} / d f=2.29$, RMSEA $=0.06, \mathrm{SRMR}=0.05, \mathrm{CFI}=0.93, \mathrm{TLI}=0.92, \mathrm{AIC}=1260.96$, and $\mathrm{BCC}=1279.90$. After $\mathrm{a}$ detailed check of the model to improve its validity and reliability, CFA was conducted again by removing items possessing lower factor loadings. Hair et al. (2019) maintained that higher loadings are more significant and confirm that the indicators are strongly associated with their related constructs. After several rounds of CFA, seven items were eliminated and led to an improved model fit: $\chi^{2}=616.45, d f=277, p<0.001, \chi^{2} / d f=2.22$, RMSEA $=0.05$, SRMR $=$ $0.05, \mathrm{CFI}=0.95, \mathrm{TLI}=0.94, \mathrm{AIC}=764.45$, and $\mathrm{BCC}=776.82$. Table 6 presents the results of the final measurement model. 
Table 6. Confirmatory Factor Analysis Results for the Main Study $(N=351)$

\begin{tabular}{|c|c|c|c|c|}
\hline Construct and Item & $\begin{array}{l}\text { Factor } \\
\text { Loading }\end{array}$ & T-value & $\mathrm{CR}$ & AVE \\
\hline \multicolumn{5}{|l|}{ Accessibility $(\alpha=0.94)$} \\
\hline I had to think for a while before I could recall this trip (R). & 0.93 & $\mathrm{~N} / \mathrm{A}^{\mathrm{a}}$ & 0.94 & 0.74 \\
\hline I had to search my memory to recall this trip (R). & 0.91 & $29.88^{* * *}$ & & \\
\hline I do not recall this trip very often $(\mathrm{R})$. & 0.78 & $20.50^{* * *}$ & & \\
\hline Since it happened, I have not thought about this trip very often (R). & 0.80 & $21.70^{* * *}$ & & \\
\hline It was difficult for me to think of this memory $(\mathrm{R})$. & 0.86 & $25.59^{* * *}$ & & \\
\hline \multicolumn{5}{|l|}{ Trip Details $(\alpha=0.85)$} \\
\hline My memory for the region(s) where I traveled is clear. & 0.82 & $\mathrm{~N} / \mathrm{A}^{\mathrm{a}}$ & 0.85 & 0.65 \\
\hline My memory for the city(ies) where I traveled is clear. & 0.84 & $18.00^{* * *}$ & & \\
\hline My memory for the destination(s) where I traveled is clear. & 0.76 & $15.80^{* * *}$ & & \\
\hline \multicolumn{5}{|l|}{ Emotional Intensity $(\alpha=0.88)$} \\
\hline This memory evokes powerful emotions. & 0.85 & $\mathrm{~N} / \mathrm{A}^{\mathrm{a}}$ & 0.88 & 0.65 \\
\hline This memory evokes strong emotions in me. & 0.83 & $18.92^{* * *}$ & & \\
\hline My emotions are very intense concerning this trip. & 0.77 & $16.90^{* * *}$ & & \\
\hline While remembering this trip now, my feelings are very intense. & 0.76 & $16.75^{* * *}$ & & \\
\hline \multicolumn{5}{|l|}{ Sharing $(\alpha=0.93)$} \\
\hline I often talk about this trip with my friends or family. & 0.90 & $\mathrm{~N} / \mathrm{A}^{\mathrm{a}}$ & 0.93 & 0.79 \\
\hline I frequently tell others about this memory. & 0.89 & $25.90^{* * *}$ & & \\
\hline I frequently talk about this trip with others. & 0.86 & $23.57^{* * *}$ & & \\
\hline I often share this memory with others. & 0.89 & $25.82^{* * *}$ & & \\
\hline \multicolumn{5}{|l|}{ Valence $(\alpha=0.86)$} \\
\hline The overall tone of this memory is quite positive. & 0.84 & $\mathrm{~N} / \mathrm{A}^{\mathrm{a}}$ & 0.87 & 0.69 \\
\hline My feelings at the time were quite positive. & 0.83 & $18.05^{* * *}$ & & \\
\hline My overall feeling about this trip is quite positive. & 0.81 & $17.68^{* * *}$ & & \\
\hline \multicolumn{5}{|l|}{ Sensory Details $(\alpha=0.84)$} \\
\hline $\begin{array}{l}\text { When I recall this memory, I can smell in my mind the things that I } \\
\text { smelled during the trip. }\end{array}$ & 0.75 & $\mathrm{~N} / \mathrm{A}^{\mathrm{a}}$ & 0.85 & 0.58 \\
\hline $\begin{array}{l}\text { When I recall this memory, I can remember tactile details related to } \\
\text { the trip. }\end{array}$ & 0.76 & $14.19^{* * *}$ & & \\
\hline $\begin{array}{l}\text { When I recall this memory, I can hear in my mind the sounds that I } \\
\text { heard during the trip. }\end{array}$ & 0.80 & $14.95^{* * *}$ & & \\
\hline $\begin{array}{l}\text { When I recall this memory, I can feel the bodily sensation that I felt } \\
\text { during the trip. }\end{array}$ & 0.74 & $13.67^{* * *}$ & & \\
\hline \multicolumn{5}{|l|}{ Vividness $(\alpha=0.84)$} \\
\hline My memory for this trip is very vivid. & 0.78 & $\mathrm{~N} / \mathrm{A}^{\mathrm{a}}$ & 0.84 & 0.65 \\
\hline My memory for this trip is very clear. & 0.83 & $16.43^{* * *}$ & & \\
\hline My memory for this trip is very detailed. & 0.80 & $15.80^{* * *}$ & & \\
\hline
\end{tabular}

Note: $\alpha=$ Cronbach's alpha; $\mathrm{CR}=$ construct reliability; AVE = average variance extracted; $(\mathrm{R})=$ Reversed items; ${ }^{* * *} p<0.001$. a. In AMOS, T-value cannot be calculated for this item since one loading is fixed to 1 .

Construct validity was evaluated based on convergent and discriminant validity. All items' standardized factor loadings were significant $(p<0.001)$, ranging from 0.74 to 0.93 (greater than the suggested 0.5 cut-off). The seven constructs also each had an average variance extracted (AVE) value above the 0.5 threshold (Kline 2016), indicating convergent validity. Discriminant validity was first examined by assessing the heterotrait-monotrait ratio (HTMT) criterion; as shown in Table 7, all interfactor correlations were below the 0.85 threshold (Henseler, Ringle, and Sarstedt 2015). Second, following Fornell and Larcker (1981), the square roots of AVE values were higher than the interconstruct correlations for all TMC subscales aside from trip details, for which the square root of the AVE $(0.81 \%)$ was slightly lower than its correlation with valence (0.82\%) (Fornell and Larcker 1981; Hair et al. 2019). Table 7 summarizes these criteria for discriminant validity. Finally, composite reliability (CR) and Cronbach's alpha values were calculated to evaluate the internal consistency of items measuring each TMCS dimension. Each dimension had a high CR (from 0.84 to 0.94) and a Cronbach's alpha greater than 0.7 , demonstrating the reliability of the measurement model. Taken together, these results confirmed the validity and reliability of the seven proposed TMCS 
dimensions.

Table 7. Results of Discriminant Validity Tests based on Heterotrait-Monotrait (HTMT) Ratio and Fornell-Larcker Criterion.

\begin{tabular}{llllllllll}
\hline & Mean & SD & AC & VI & SD & EI & VA & TD & SH \\
\hline Accessibility (AC) & 4.65 & 1.83 & $\mathbf{0 . 8 6}$ & 0.40 & 0.10 & 0.23 & 0.48 & 0.53 & 0.01 \\
Vividness (VI) & 5.80 & 0.96 & 0.37 & $\mathbf{0 . 8 0}$ & 0.74 & 0.67 & 0.70 & 0.79 & 0.40 \\
Sensory Details (SD) & 5.35 & 1.12 & 0.06 & 0.74 & $\mathbf{0 . 7 6}$ & 0.73 & 0.46 & 0.51 & 0.65 \\
Emotional Intensity (EI) & 5.53 & 1.00 & 0.19 & 0.67 & 0.72 & $\mathbf{0 . 8 1}$ & 0.48 & 0.59 & 0.53 \\
Valence (VA) & 5.89 & 1.00 & 0.46 & 0.71 & 0.46 & 0.48 & $\mathbf{0 . 8 3}$ & 0.83 & 0.26 \\
Trip Details (TD) & 5.85 & 1.04 & 0.50 & 0.80 & 0.52 & 0.61 & 0.82 & $\mathbf{0 . 8 1}$ & 0.29 \\
Sharing (SH) & 4.99 & 1.36 & -0.06 & 0.40 & 0.65 & 0.52 & 0.26 & 0.28 & $\mathbf{0 . 8 9}$ \\
\hline
\end{tabular}

Note: SD = Standard Deviation. The bold diagonal elements are the squared root of AVE; Above diagonal elements are the Heterotrait-Monotrait (HTMT) ratio; below diagonal elements are correlations between the constructs for Fornell-Larcker Criterion.

\section{Nomological and Predicative Validity}

To assess nomological validity, a theoretical relationship was anticipated between two related constructs identified from prior research and a theoretical foundation. According to the reminiscence functions of autobiographical memories, the directive reminiscence function leads to future behavior, whereas the social reminiscence function can be achieved by sharing memories with others (Bluck and Alea 2011; H. Kim and Chen 2019). Thus, two constructsrevisit intention and WOM (correlation coefficient $r=0.74, p<0.01$ ) were included in the model. Both constructs were significantly correlated with the seven TMCS dimensions, indicating strong nomological validity as shown in Table 8.

Table 8. Nomological Validity Test: Correlation Coefficients $(N=351)$

\begin{tabular}{lll}
\hline & Revisit Intention & Word-of-Mouth \\
\hline Accessibility & $0.38^{* *}$ & $0.38^{* *}$ \\
Vividness & $0.59^{* *}$ & $0.54^{* *}$ \\
Sensory Details & $0.45^{* *}$ & $0.40^{* *}$ \\
Emotional Intensity & $0.43^{* *}$ & $0.43^{* *}$ \\
Valence & $0.63^{* *}$ & $0.64^{* *}$ \\
Trip Details & $0.65^{* *}$ & $0.60^{* *}$ \\
Sharing & $0.32^{* *}$ & $0.33^{* *}$ \\
\hline
\end{tabular}

Note: ${ }^{* *} p<0.01$.

After investigating interconstruct correlations, predictive validity was assessed to determine whether scores related to tourism memory could predict scores on revisit intention and WOM. Structural equation modeling (SEM) was applied using partial least squares (PLS) estimation (Hair, Ringle, and Sarstedt 2011). Following Wang, Li, and Xu (2019), a two-stage approach was adopted for PLS-SEM in SmartPLS 3. The first-stage model was assessed based on reflective constructs; second-stage models applied formative and reflective construct measures. In particular, tourism memory was evaluated as a formative construct in the secondstage model (see Figure 1).

The overall model fit was evaluated by SRMR, returning respective values of 0.05 (firststage model) and 0.04 (second-stage model). To assess in-sample predictive power, the coefficient of determination $\left(R^{2}\right)$, which represents the degree of variance in endogenous latent variables, was examined in the structural model (Hair et al. 2014). Generally, the threshold for $R^{2}$ value is greater than $0.25 . R^{2}$ value greater than 0.50 is moderate, while $R^{2}$ value greater than 0.75 is substantial (Hair et al. 2014). The $R^{2}$ values of the first-stage model were 0.52 for revisit intention and 0.51 for $\mathrm{WOM}$; those for the second-stage model were 0.52 for revisit intention and 0.50 for WOM. To further evaluate the structural model, $f^{2}$ effect sizes were 
calculated following Cohen's (1988) guideline: the $f^{2}$ value of at least $0.02,0.15$, or 0.35 reflects a small, medium, or large effect size, respectively. In the first-stage model, trip details and valence had small effect sizes relative to revisit intention; valence and sharing had medium and small effect sizes, respectively, relative to WOM. The second-stage model revealed that tourism memory had a large effect size in relation to revisit intention and WOM.

Path coefficients were estimated via bias-corrected bootstrapping with 5,000 subsamples. Vividness, trip details, valence, and accessibility were each significantly associated with revisit intention. Among them, trip details had the strongest effect on revisit intention $(0.26, p<0.01)$. Valence, accessibility, and sharing were significantly correlated with WOM as well, with valence exhibiting the strongest relationship $(0.41, p<0.001)$. In the second-stage model, tourism memory had strong relationships with revisit intention $(0.73, p<0.001)$ and WOM $(0.71, p<0.001)$. These findings are presented in Table 9 .

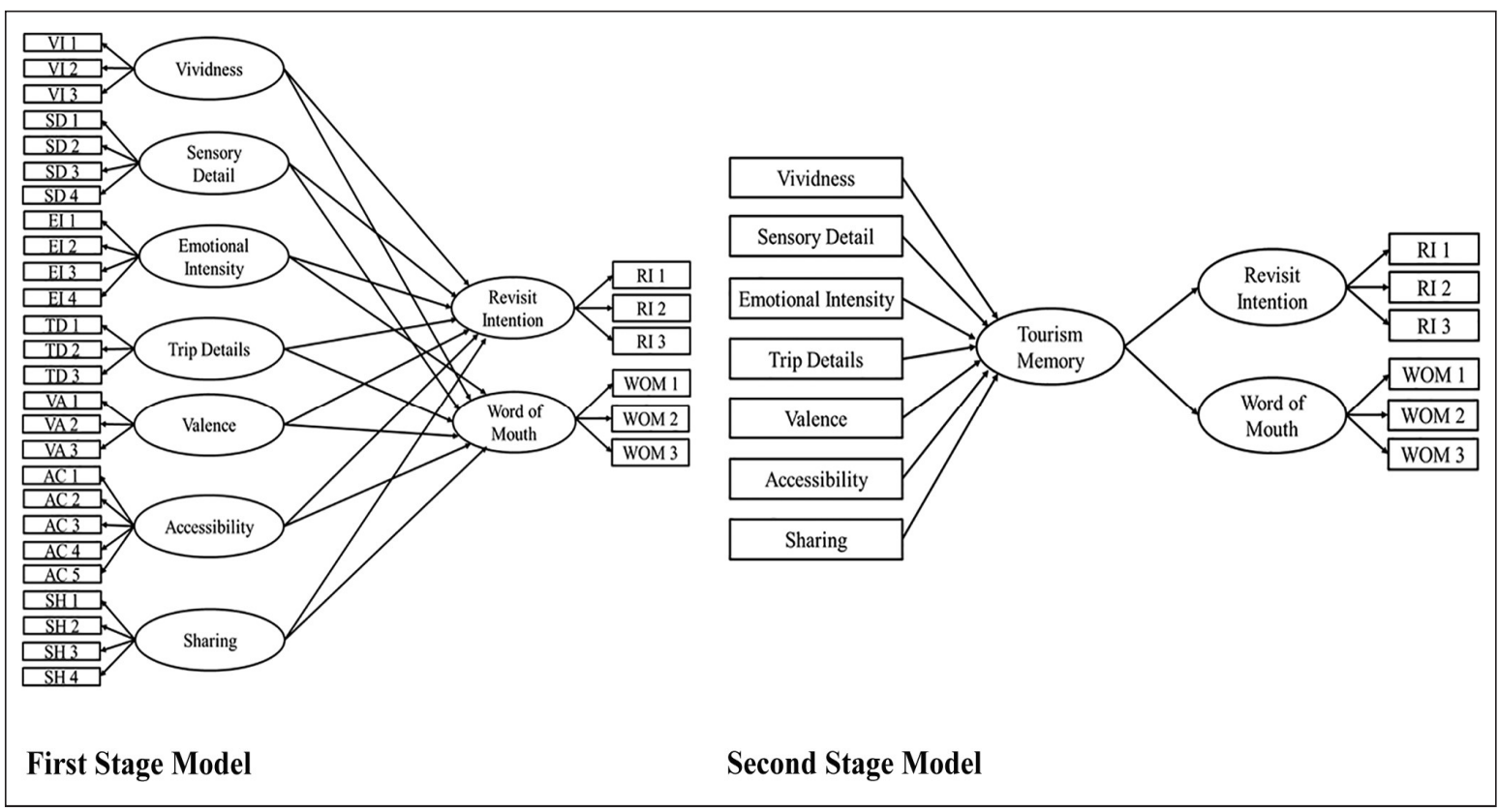

Figure 1. Two-stage model 
Table 9. Estimated Path Coefficients, Effect Size: First-Stage and Second-Stage Model $(N=351)$

\begin{tabular}{|c|c|c|c|c|c|c|c|c|}
\hline \multirow[b]{2}{*}{ Model } & \multirow[b]{2}{*}{ Paths } & \multirow[b]{2}{*}{ Coefficients } & \multirow[b]{2}{*}{ T Statistics } & \multicolumn{2}{|c|}{ BCa Confidence Intervals } & \multirow[b]{2}{*}{ Effect Sizes $\left(f^{2}\right)$} & \multicolumn{2}{|c|}{$\begin{array}{l}\text { Coefficient of } \\
\text { Determination }\left(R^{2}\right)\end{array}$} \\
\hline & & & & $2.5 \%$ & $97.5 \%$ & & RI & WOM \\
\hline \multirow[t]{14}{*}{ First-Stage Model } & Vividness $\rightarrow$ RI & $0.13^{*}$ & 2.01 & 0.013 & 0.276 & 0.01 & 0.52 & 0.51 \\
\hline & Sensory Details $\rightarrow$ RI & $0.11^{\mathrm{ns}}$ & 1.41 & -0.035 & 0.270 & 0.01 & & \\
\hline & Emotional Intensity $\rightarrow$ RI & $-0.02^{\text {ns }}$ & 0.50 & -0.171 & 0.106 & 0.01 & & \\
\hline & Trip Details $\rightarrow$ RI & $0.26^{* *}$ & 2.97 & 0.097 & 0.455 & 0.05 & & \\
\hline & Valence $\rightarrow$ RI & $0.26^{* *}$ & 2.83 & 0.110 & 0.463 & 0.06 & & \\
\hline & Accessibility $\rightarrow$ RI & $0.09^{*}$ & 2.15 & 0.012 & 0.187 & 0.01 & & \\
\hline & Sharing $\rightarrow$ RI & $0.09^{\text {ns }}$ & 1.83 & -0.005 & 0.199 & 0.01 & & \\
\hline & Vividness $\rightarrow$ WOM & $0.08^{\mathrm{ns}}$ & 1.27 & -0.041 & 0.211 & 0.01 & & \\
\hline & Sensory Details $\rightarrow$ WOM & $0.01^{\mathrm{ns}}$ & 0.12 & -0.123 & 0.149 & 0.00 & & \\
\hline & Emotional Intensity $\rightarrow$ WOM & $0.04^{\mathrm{ns}}$ & 0.57 & -0.085 & 0.158 & 0.01 & & \\
\hline & Trip Details $\rightarrow$ WOM & $0.13^{\mathrm{ns}}$ & 1.34 & -0.063 & 0.316 & 0.01 & & \\
\hline & Valence $\rightarrow$ WOM & $0.41^{* * *}$ & 5.30 & 0.255 & 0.564 & 0.15 & & \\
\hline & Accessibility $\rightarrow$ WOM & $0.10^{*}$ & 2.21 & 0.012 & 0.202 & 0.01 & & \\
\hline & Sharing $\rightarrow$ WOM & $0.15^{* *}$ & 2.98 & 0.056 & 0.257 & 0.03 & & \\
\hline \multirow[t]{2}{*}{ Second-Stage Model } & Tourism Memory $\rightarrow$ RI & $0.73^{* * *}$ & 24.15 & 0.651 & 0.770 & 1.09 & 0.52 & 0.50 \\
\hline & Tourism Memory $\rightarrow$ WOM & $0.71^{* * *}$ & 20.76 & 0.638 & 0.772 & 1.03 & & \\
\hline
\end{tabular}

Note: Results were based on bootstrapping with 5,000 subsamples; RI = Revisit Intention, WOM = Word-of-Mouth.

${ }^{*} p<0.05,{ }^{* *} p<0.01,{ }^{* * *} p<0.001 ;$ ns $=$ not significant. 


\section{Discussion and Implications}

The proposed TMCS illuminates a new direction in tourism memory research by integrating tourism experiences and autobiographical memory phenomenology. The TMCS is unique compared with previous scales. The TMCS includes essential memory dimensions that can best explain tourism memory and its associated outcomes such as WOM and revisit intention. Specifically, memories derived from generic, sensory, and affective elements of tourism experiences are considered a key source of information that people can access for sharing their memories and making a future trip (Agapito, Pinto, and Mendes 2017; H. Kim and Chen 2019; Marschall 2014; Prayag, Hosany, and Odeh 2013; Tung and Ritchie 2011a; Wood 2020). Furthermore, the TMCS focuses on terms (e.g., "this trip," "my memory") that can include both a single event and multiple events. Conversely, previous scales tended to use "this event" to assess autobiographical memory, although this approach could limit respondents' access to generic event-level information. Respondents in the present study recalled multiple events during memory-writing tasks, such as "I visited so many shops and dined in some really nice restaurants"; this example implies that people might evaluate their memories by accessing multiple events that occurred during a trip (Conway and Pleydell-Pearce 2000; Rubin, Schrauf, and Greenberg 2003). Thus, terms used in the TMCS can better gauge distinct memory characteristics.

Based on the theoretical foundation of this work, cognitive-affective-behavioral links of tourism memory were articulated through the correlations among seven dimensions: accessibility, trip details, vividness, sensory details, valence, emotional intensity, and sharing. First, the dimensions of accessibility, trip details, vividness, and sensory details explained the cognitive process involved in accessing autobiographical knowledge. Accessibility enables people to access tourism-related memories. This factor covers individuals' ability to access tourism memories along with the frequency with which these memories have been recalled. The most general autobiographical knowledge, especially place details, is included in recalled trip details. General knowledge is paramount to tourism memory because it acts as a channel through which individuals can access more specific memories. Vividness relies heavily on information about what a person observed in general. As Rubin (2005) argued, visual memories strengthen recollection overall. Thus, visual information is vital when accessing tourismrelated memories. Sensory details encompass specific autobiographical knowledge such as hearing, scents, bodily sensations, and tactile stimuli. To reach this level of specificity, most respondents in the present study may have searched through their memories while completing related questionnaire items. Second, the evaluation of memory valence and the evocation of intense emotion are related to cognitive-affective processing. Valence reflects the way tourism memories are perceived to be positive. Tung and Ritchie (2011a) and J. H. Kim, Ritchie, and McCormick (2012) stated that tourism experiences are often remembered positively. Our findings also highlighted positive valence as a key indicator in the TMCS. Emotional intensity refers to the intensity of emotions aroused at the time of retrieval and immediately after recalling tourism-related memories; that is, recalled memories can stimulate emotions tourists felt during a trip (Speer, Bhanji, and Delgado 2014). Lastly, the social function of autobiographical memory is represented by sharing. Sharing pertains to the frequency with which an individual talks with or to others about tourism memories (Jepson, Stadler, and Spencer 2019). Sharing is especially useful for predicting actual behavior, such as whether individuals share their tourism memories after a trip. Above all, the integrated characteristics of tourism memory play significant roles in predicting tourists' revisit intentions and WOM (Agapito, Pinto, and Mendes 2017; H. Kim and Chen 2019; Wirtz et al. 2003; Yin, Poon, and Su 2017).

The TMCS (26 items), as a novel seven-dimension scale, also addresses the limitations of earlier scales. Previous scales on autobiographical memory have provided meaningful insights 
into the relationship between experiences and autobiographical memories. The TAMS ( 8 items; Jorgenson et al. 2019) is a useful instrument for examining specific tourism experiences, while the measure does not cover several key phenomenological characteristics of tourism memory, such as trip details and sensory details. Moreover, CFA processes to validate the scale were not performed regarding convergent and discriminant validity. Although the MEQ (63 items; Sutin and Robins 2007) and AMCQ (63 items; Boyacioglu and Akfirat 2015) are psychometrically comprehensive, they are time-consuming when incorporated into a complex research model. Lengthy scales may also be difficult to administer to specific populations (e.g., older individuals) if respondents possess low literacy (Stanton et al. 2002). The MEQ-SF (31 items; Luchetti and Sutin 2016) is parsimonious and comprehensive in capturing the key phenomenology of autobiographical memory; however, its valence dimension contains only two items.

To overcome the above measurement constraints, this study followed a rigorous scale development process (Churchill 1979; Boley and McGehee 2014) to extract a seven-dimension model via initial EFA and confirmation via CFA. All scale dimensions contained at least three items. The model revealed strong internal consistency, content validity, convergent validity, nomological validity, and predictive validity along with adequate discriminant validity. Conway (2005, p. 613) argued that the main tenet of episodic memory is to "retain the summary records sensory-perceptual-conceptual-affective processing derived from working memory." Given that the TMCS subconstructs are inherently highly correlated, the discriminant validity outcomes in the present study were satisfactory.

\section{Theoretical Implications}

Tourism memory was defined and underpinned by phenomenology, autobiographical knowledge base within SMS, affective responses on retrieval, and a social function of autobiographical memory. As such, this work makes theoretical contributions to the tourism literature by striving to understand tourism memory in terms of affording travelers memorable experiences that elicit positive behavior.

This study identified significant characteristics of general autobiographical knowledge (i.e., trip details) and specific autobiographical knowledge (i.e., vividness and sensory details). Findings imply that individuals recall tourism memories by accessing salient information represented by different levels of memory specificity. Therefore, the top-down strategy from general to specific information might elucidate how people process information derived from tourism memories. In this study, individuals rarely accessed sensory knowledge on retrieving tourism memories; general knowledge and visual imagery (i.e., vividness) instead predominantly represented these memories. Tourism researchers should thus consider the types of information people initially and deeply access when recalling tourism memories.

Tourism studies have often evaluated the emotional components of tourism experiences and destinations. However, little work has determined whether tourism memories are in fact processed positively and whether intense emotions influence people while and immediately after recalling tourism experiences. The TMCS thoroughly reflects associated phenomena, thereby enabling tourism scholars to develop more diverse approaches to assessing emotional tourism memory and related variables.

Lastly, this study predicted a relationship between tourism memory and behavior by investigating individuals' recall of personally important tourism experiences, their past visit frequency, and future behavioral intentions (i.e., revisit intentions and WOM). In line with the directive function of autobiographical memory, memories can help people to predict future behavior. Furthermore, the enhanced social function of autobiographical memory was underlined by confirming a significant relationship between the dimension of sharing, other 
dimensions of the TMCS, and WOM. In sum, tourism memory involves more than the collection of autobiographical knowledge; it leads to actual behavior that nurtures both an individual's memory and tourism destinations.

\section{Managerial Implications}

Destination marketing organizations and travel agencies have long paid attention to the quality of tourist products (e.g., attractions and tours) to provide consumers consistent travel experiences. These firms often focus on target sociodemographic profiles and consumers' motivations with an overarching goal of increasing customers' satisfaction and loyalty. However, these approaches cannot necessarily predict future tourist behavior. Recently, coronavirus (COVID-19) has challenged the tourism industry by limiting travelers' mobility. Tourism organizations should realize that travel patterns will likely shift from general to selective experience consumption based on evolving customer needs (e.g., safety) in the current tourism landscape. It is therefore imperative for tourism organizations to reconsider core characteristics of their products and related memories. The TMCS could contribute to organizational market research because this instrument is designed to examine memory contents and tourism memory characteristics tied to cognitive-affective-behavioral aspects of autobiographical memory.

The TMCS holds practical utility in three respects. First, marketers can use the scale to identify which memory characteristics customers value most or least. Various memories (e.g., vivid, sensory, emotional, and shared memories) can be evoked by exposing customers to the most memorable parts of tourism experiences based on travel themes (Agapito, Pinto, and Mendes 2017; Jepson, Stadler, and Spencer 2019; J. H. Kim, Ritchie, and McCormick 2012; Speer, Bhanji, and Delgado 2014). Vivid and sensory memories should be especially predictive of consumer behavior, as sensory elements can directly influence destination selection (Agapito, Pinto, and Mendes 2017; Lv, Li, and McCabe 2020).

Second, tourism organizations can use the TMCS to confirm whether their products elicit travelers' valence and emotions as intended. These firms can also solicit tourists' general evaluations about product offerings. In investigating emotional responses to customer experiences, the combination of the memory-writing task and the TMCS can pinpoint exactly when customers experience positive feelings and intense emotions. More specifically, marketers can identify when positive and negative emotions manifest through written memories. These personnel can also review tourists' overall trip evaluations using two dimensions: valence and emotional intensity.

Lastly, the TMCS can serve as a foundational resource to promote product-related storytelling and positive WOM that customers can trust when choosing future travel destinations. As discussed above, accessibility, valence, and sharing all fostered WOM after tourism memory recall. Customers who have experienced a product that encourages positive memorability are likely to engage in far-reaching WOM. Thus, the TMCS can be broadly adopted to build product stories and formulate desired product images.

\section{Limitations and Future Research}

This study presents a psychometrically comprehensive, reliable, and valid tourism memory scale while enriching the tourism literature. However, several limitations should be addressed in the future. The pilot and main studies in this research were each conducted with American samples; subsequent work should include cross-cultural studies to test the generalizability of the TMCS. Additionally, the scale's correlation between trip details and valence had slightly low discriminant validity because these constructs are conceptually related (Conway 2005). Such validity could be enhanced by manipulating memory types or investigating more specific 
trip-related events in the future. Researchers could therefore modify the TMCS using theoretical criteria and validate the scale to confirm a final instrument.

Lastly, the antecedents and consequences of tourism memories should be explored further. This research tested the scale's nomological and predictive validity by examining the consequences of tourism memories, such as individuals' revisit intentions and WOM. In addition to behavioral intention, the TMCS should be further validated by investigating other related constructs to determine the instrument's applicability in diverse contexts. Studies should particularly test antecedents (e.g., customer satisfaction) and consequences (e.g., happiness) with respect to the direct or mediating effects of tourism memory.

\section{References}

Agapito, D., P. Pinto, and J. Mendes. 2017. “Tourists' Memories, Sensory Impressions and Loyalty: In Loco and Post-Visit Study in Southwest Portugal." Tourism Management 58: $108-18$.

Akaike, H. 1987. "Factor analysis and AIC." Psychometrika 52:317-32.

Alea, N., and S. Bluck. 2003. "Why are you telling me that? A conceptual model of the social function of autobiographical memory." Memory 11(2): 165-78.

Anderson, D., and H. Shimizu. 2007. "Factors Shaping Vividness of Memory Episodes: Visitors' Long-Term Memories of the 1970 Japan World Exposition.” Memory 15 (2): 177-91.

Arbuckle, J. L. 2016. IBM ${ }^{\circledR}$ SPSS $^{\circledR}$ Amos $^{\mathrm{TM}}$ User's Guide. Armonk, NY: IBM.

Ballantyne, R., J. Packer, and L. Sutherland. 2011. "Visitors' Memories of Wildlife Tourism: Implications for the Design of Powerful Interpretive Experiences.” Tourism Management 32(4): 770-79.

Bluck, S., and N. Alea. 2011. "Crafting the Tale: Construction of a Measure to Assess the Functions of Autobiographical Remembering." Memory 19 (5): 470-86.

Bluck, S., N. Alea, T. Habermas, and D. C. Rubin. 2005. "A Tale of Three Functions: The Self-Reported Uses of Autobiographical Memory.” Social Cognition 23 (1): 91-117.

Boley, B. B., E. Jordan, and K. M. Woosnam. 2020. "Reversed Polarity Items in Tourism Scales: Best Practice or Dimensional Pitfall?" Current Issues in Tourism 1-13.

Boley, B. B., and N. G. McGehee. 2014. "Measuring empowerment: Developing and validating the Resident Empowerment through Tourism Scale (RETS)." Tourism Management 45:85-94.

Boley, B. B., M. Strzelecka, E. Yeager, M. A. Ribeiro, K. D. Aleshinloye, K. M. Woosnam, and B. P. Mimbs. 2021. "Measuring Place Attachment with the Abbreviated Place Attachment Scale (APAS)." Journal of Environmental Psychology 74:101577.

Boyacioglu, I., and S. Akfirat. 2015. "Development and psychometric properties of a new measure for memory phenomenology: The Autobiographical Memory Characteristics Questionnaire." Memory 23 (7): 1070-92.

Browne, M. W., and R. Cudeck. 1989. "Single Sample Cross-Validation Indices for Covariance Structures.” Multivariate Behavioral Research 24 (4): 445-55.

Carpenter, S. 2018. "Ten steps in scale development and reporting: A guide for researchers." Communication Methods and Measures 12:25-44.

Churchill, G. A. 1979. "A paradigm for developing better measures of marketing constructs." Journal of Marketing Research 16:64-73.

Cohen, J. 1988. Statistical Power Analysis for the Behavioral Sciences. 2nd ed. Hillsdale, NJ: Lawrence Erlbaum.

Conway, M. A. 2005. "Memory and the self.” Journal of Memory and Language 53:594-628.

Conway, M. A. and C. W. Pleydell-Pearce. 2000. "The construction of autobiographical 
memories in the self-memory system." Psychological Review 107:261-88.

Conway, M. A., and H. L. Williams. 2008. “Autobiographical memory.” In Learning and Memory: A Comprehensive Reference, edited by J. H. Byrne, 893-909. Oxford: Elsevier Ltd.

DeVellis, R. 2016. Scale Development Theory and Applications. 4th ed. Thousand Oaks, CA: Sage.

Fivush, R. 2011. "The Development of Autobiographical Memory.” Annual Review of Psychology 62 (1): 559-82.

Fornell, C., and F. Larcker. 1981. "Evaluating Structural Equation Models with Unobservable Variables and Measurement Error." Journal of Marketing Research 18 (1): 39-50.

Hair, J. F., W. C. Black, B. J. Babin, and R. E. Anderson. 2019. Multivariate Data Analysis, 8th ed. Boston: Cengage.

Hair, J. F., G. T. M. Hult, C. M. Ringle, and M. Sarstedt. 2014. A Primer on Partial Least Squares Structural Equation Modeling. Thousand Oaks, CA: Sage.

Hair, J. F., C. M. Ringle, and M. Sarstedt. 2011. "Pls-sem: Indeed a silver bullet." Journal of Marketing theory and Practice 19 (2): 139-52.

Haynes, S. N., D. C. S. Richard, and E. S. Kubany. 1995. "Content validity in psychological assessment: A functional approach to concepts and methods." Psychological Assessment $7: 238-47$.

Henseler, J., C. Ringle, and M. Sarstedt. 2015. "A new criterion for assessing discriminant validity in variance-based structural equation modeling." Journal of the Academy of Marketing Science 43 (1): 115-35.

Hinkin, T. R. 1995. "A review of scale development practices in the study of organizations." Journal of Management 21 (5): 967-88.

Hu, L., and P. M. Bentler. 1995. "Evaluating Model Fit.” In Structural Equation Modeling: Concepts: Issues and Applications, edited by R. Hoyle. Thousand Oaks, CA: Sage.

$\mathrm{Hu}, \mathrm{L}$., and P. M. Bentler. 1999. "Cutoff criteria for fit indexes in covariance structure analysis: Conventional criteria versus new alternatives.” Structural Equation Modeling: A Multidisciplinary Journal 6 (1): 1-55.

Jepson, A., R. Stadler, and N. Spencer. 2019. "Making positive family memories together and improving quality-of-life through thick sociality and bonding at local community festivals and events." Tourism Management 75:34-50.

Johnson, M. K., M. A. Foley, A. G. Suengas, and C. L. Raye. 1988. "Phenomenal characteristics of memories for perceived and imagined autobiographical events." Journal of Experimental Psychology: General 117 (4): 371-76.

Jorgenson, J., N. Nickerson, D. Dalenberg, J. Angle, E. Metcalf, and W. Freimund. 2019. "Measuring Visitor Experiences: Creating and Testing the Tourism Autobiographical Memory Scale.” Journal of Travel Research 58 (4): 566-78.

Kim, H., and J. S. Chen. 2019. "The memorable travel experience and its reminiscence functions." Journal of Travel Research 58 (4): 637-49.

Kim, H., and J. S. Chen. 2021. "Memorable Travel Experiences: Recollection vs Belief." Tourism Recreation Research 46 (1): 124-31.

Kim, J., and D. R. Fesenmaier. 2017. "Sharing tourism experiences: The post-trip experience." Journal of Travel Research 56 (1): 28-40.

Kim, J. H. 2010. "Determining the Factors Affecting the Memorable Nature of Travel Experiences." Journal of Travel and Tourism Marketing 27 (8): 780-96.

Kim, J. H. 2014. "The antecedents of memorable tourism experiences: The development of a scale to measure the destination attributes associated with memorable experiences." Tourism Management 44:34-45.

Kim, J. H. 2020. “Destination Attributes Affecting Negative Memory: Scale Development and Validation." Journal of Travel Research. Published online December 10. doi:10.1177/0047287520977725. 
Kim, J. H., and S. C. Jang. 2016. "Memory Retrieval of Cultural Event Experiences:

Examining Internal and External Influences.” Journal of Travel Research 55 (3): 322-39.

Kim, J. H., J. R. B. Ritchie, and B. McCormick. 2012. "Development of a Scale to Measure Memorable Tourism Experiences.” Journal of Travel Research 51 (1): 12-25.

Kim, J. H. and H. Youn. 2017. "How to Design and Deliver Stories about Tourism Destinations." Journal of Travel Research 56 (6): 808-20.

Kline, R. B. 2016. Principles and Practice of Structural Equation Modeling. 4th ed. New York: The Guilford Press.

Larsen, S. 2007. "Aspects of a Psychology of the Tourist Experience." Scandinavian Journal of Hospitality and Tourism 7 (1): 7-18.

Liu, Y., Y. Yao, and D. X. F. Fan. 2020. "Evaluating Tourism Market Regulation from Tourists' Perspective: Scale Development and Validation.” Journal of Travel Research 59 (6): 975-92.

Luchetti, M., and A. R. Sutin. 2016. "Measuring the Phenomenology of Autobiographical Memory: A Short Form of the Memory Experiences Questionnaire." Memory 24 (5): 592-602.

Lv, X., C. Li, and S. McCabe. 2020. "Expanding Theory of Tourists' Destination Loyalty: The Role of Sensory Impressions." Tourism Management 77:104026.

Marschall, S. 2014. "Tourism and remembrance: the journey into the self and its past." Journal of Tourism and Cultural Change 12 (4): 335-48.

Meesters, C., H. Merckelbach, P. Muris, and I. Wessel. 2000. "Autobiographical memory and trauma in adolescent". Journal of Behavior Therapy and Experimental Psychiatry 31:2939.

Mowen, J. C., and K. E. Voss. 2008. "On building better construct measures: Implications of a general hierarchical model." Psychology and Marketing 25(6): 485-505.

Netemeyer, R. G., W. Bearden, and S. Sharma. 2003. Scaling procedures: Issues and applications. Thousand Oaks, CA: Sage.

Otoo, F. E., S. S. Kim, and Y. Choi. 2021. "Developing a Multidimensional Measurement Scale for Diaspora Tourists' Motivation.” Journal of Travel Research 60 (2): 417-33.

Papadimitriou, D., K. Kaplanidou, and A. Apostolopoulou. 2018. "Destination Image Components and Word-of-mouth Intentions in Urban Tourism: A Multigroup Approach." Journal of Hospitality \& Tourism Research 42 (4): 503-27

Pearce, P. L., and J. Packer. 2013. "Minds on the move: New links from psychology to tourism." Annals of Tourism Research 40:386-411.

Piolino, P. B. Desgranges, K. Benali, and F. Eustache. 2002. "Episodic and semantic remote autobiographical memory in ageing." Memory 10 (4): 239-57.

Potheegadoo, J. F. Berna, C. Cuervo-Lombard., and J. M. Danion. 2013. "Field visual perspective during autobiographical memory recall is less frequent among patients with schizophrenia." Schizophrenia Research 150: 88-92.

Prayag, G. S. Hosany, and K. Odeh. 2013. "The Role of Tourists' Emotional Experiences and Satisfaction in Understanding Behavioral Intentions." Journal of Destination Marketing and Management 2 (2): 118-27.

Rahmani, K., J. Gnoth, and D. Mather. 2019. "A Psycholinguistic View of Tourists' Emotional Experiences.” Journal of Travel Research 58 (2): 192-206.

Rasmussen, A. S., and D. Berntsen. 2009. "Emotional Valence and the Functions of Autobiographical Memories: Positive and Negative Memories Serve Different Functions." Memory and Cognition 37 (4): 477-92.

Ribeiro, M. A., K. M. Woosnam, P. Pinto, and J. A. Silva. 2018. "Tourists' Destination Loyalty through Emotional Solidarity with Residents: An Integrative Moderated Mediation Model." Journal of Travel Research 57 (3): 279-95.

Ribeiro, M. A., P. Pinto, J. A. Silva, and K. M. Woosnam. 2018. "Examining the Predictive Validity of SUS-TAS with Maximum Parsimony in Developing Island Countries." 
Journal of Sustainable Tourism 26 (3): 379-98.

Rubin, D. C. 2005. "A basic-systems approach to autobiographical memory." Current Directions in Psychological Science 14(2): 79-83.

Rubin, D. C., R. W. Schrauf, and D. L. Greenberg. 2003. "Belief and recollection of autobiographical memories." Memory and Cognition 31:887-901.

Schwartz, B. 2011. Memory: Foundations and applications. Thousand Oaks: Sage.

Soulard, J., N. McGehee, and W. Knollenberg. 2021. "Developing and Testing the

Transformative Travel Experience Scale (TTES)." Journal of Travel Research 60 (5): 923-46.

Speer, M. E., J. P. Bhanji, and M. R. Delgado. 2014. "Savoring the Past: Positive Memories Evoke Value Representations in the Striatum.” Neuron 84 (4): 847-56.

Speer, M. E., and M. R. Delgado. 2019. "The social value of positive autobiographical memory retrieval.” Journal of Experimental Psychology: General 194:790-99.

Stanton, J. M., E. F. Sinar, W. K. Balzer, and P. C. Smith. 2002. "Issues and strategies for reducing the length of self-report scales." Personnel Psychology 55:167-94.

Sutin, A. R., and R. W. Robins. 2007. "Phenomenology of autobiographical memories: The Memory Experiences Questionnaire.” Memory 15:390-411.

Tabachnick, B. G., and L. S. Fidell. 2013. Using Multivariate Statistics. 6th ed. Boston: Pearson.

Tulving, E. 1972. "Episodic and Semantic Memory." In Organization of Memory, edited by E. Tulving and W. Donaldson, 381-402. New York: Academic Press.

Tulving, E. 2002. "Episodic memory: From mind to brain." Annual Review of Psychology 53 (1): $1-25$.

Tulving, E., D. L. Schacter, D. R. McLachlan, and M. Moscovitch. 1988. "Priming of semantic autobiographical knowledge: A case study of retrograde amnesia." Brain and Cognition 8:3-20

Tung, V. W. S., and J. R. B. Ritchie. 2011a. "Exploring the Essence of Memorable Tourism Experiences." Annals of Tourism Research 38 (4): 1367-86.

Tung, V. W. S., and J. R. B. Ritchie. 2011b. "Investigating the Memorable Experiences of the Senior Travel Market: An Examination of the Reminiscence Bump." Journal of Travel and Tourism Marketing 28 (3): 331-43.

Um S., K. Chon, and Y. Ro. 2006. "Antecedents of revisit intention.” Annals of Tourism Research 33 (4): 1141-58.

Wang, C., G. Li, and H. Xu. 2019. "Impact of lifestyle-oriented motivation on small tourism enterprises' social responsibility and performance." Journal of Travel Research 58:1146160.

Watson, L. A., D. Berntsen, W. Kuyken, and E. R. Watkins. 2012. "The characteristics of involuntary and voluntary autobiographical memories in depressed and never depressed individuals." Consciousness and Cognition 21 (3): 1382-392.

Weaver, P., K. Weber, and K. McCleary (2007). "Destination Evaluation: The Role of Previous Travel Experience and Trip Characteristics.” Journal of Travel Research, 45 (3): 333-44.

Wirtz, D., J. Kruger., C. N. Scollon, and E. Diener. 2003. "What to Do on Spring Break? The Role of Predicted, on-Line, and Remembered Experience in Future Choice." Psychological Science 14 (5): 520-24.

Wood, E. H. 2020. "I Remember How We All Felt: Perceived Emotional Synchrony through Tourist Memory Sharing." Journal of Travel Research 59 (8): 1339-52.

Worthington, R. L., and T. A. Whittaker. 2006. "Scale Development Research A Content Analysis and Recommendations for Best Practices." The Counseling Psychologist, 34 (6): 806-38.

Yin, C. Y., P. Poon, and J. L. Su. 2017. "Yesterday once more? Autobiographical memory evocation effects on tourists' post-travel purchase intentions toward destination products." 
Tourism Management 61:263-74.

Ziegler, M., C. J. Kemper, and P. Kruyen. 2014. "Short scales-Five misunderstandings and ways to overcome them." Journal of Individual Differences 35 (4): 185-89. 